\title{
Two-year mortality of patients with COPD in primary health care: an observational study
}

This article was published in the following Dove Press journal:

International Journal of General Medicine

4 October 2012

Number of times this article has been viewed

\section{Markos Minas \\ loanna Verrou-Katsarou \\ Parthena Mystridou \\ Eleni Apostolidou \\ Chrisi Hatzoglou \\ Konstantinos I \\ Gourgoulianis}

Respiratory Medicine Department, University of Thessaly Medical School, Larissa, Greece
Correspondence: loanna Verrou-Katsarou Respiratory Medicine Department, University Hospital of Larissa, Mezourlo, 4I I I 0 Larissa, Greece $\mathrm{Tel}+302413502896$

Email ioanvk@freemail.gr
Background: Chronic obstructive pulmonary disease (COPD) remains a significant cause of morbidity and mortality, with high rates of underdiagnosis. There are no studies about following up COPD patients in primary health care. The aim of the current study was to estimate two-year mortality for COPD patients in primary care and assess the parameters associated with mortality.

Methods: A total of 263 patients with a new COPD diagnosis were followed up for two years. Follow-up included phone contacts every six months for assessment of vital status, and re-examination visits every year after the initial diagnosis. Visits included performance on spirometry, assessment of smoking status, evaluation of adherence with treatment, and assessment of the number of exacerbations during the previous year.

Results: One hundred and eighteen patients with COPD completed the study. The overall mortality was $27.9 \%$. Most patients had quit smoking two years after the initial diagnosis, whereas the percentage of patients showing high adherence with treatment was $68 \%$. Parameters associated with two-year mortality were age and coronary heart disease comorbidity.

Conclusion: The mortality of patients with COPD in primary care remains significantly high, whereas adherence with treatment remains significant low. Age, smoking status, and a history of depression are major determinants of mortality in primary health care.

Keywords: chronic obstructive pulmonary disease, mortality, primary health care, depression

\section{Background}

Chronic obstructive pulmonary disease (COPD) is a leading cause of morbidity and mortality worldwide. According to the Global Initiative for Chronic Obstructive Lung Disease (GOLD) guidelines, COPD is a preventable and treatable disease characterized by airflow obstruction that is not fully reversible and is related to the inflammatory response of the lung to noxious particles or gases. The main risk factor for the development of the disease is smoking. ${ }^{1}$

The prevalence of COPD varies widely between countries, and underdiagnosis remains significant. Clinical and laboratory tools have been used to diagnose COPD. ${ }^{2}$ In primary health care, spirometry, chronic respiratory symptoms, and questionnaires have been tested, with variable results. For example, van Schayck et al showed that smokers over 60 years of age with cough had a $48 \%$ chance of having airways obstruction. ${ }^{3}$ Questionnaires for early detection of patients with COPD in primary care have also been developed with variable results, ${ }^{4,5}$ whereas Buffels et al showed that office spirometry is an essential tool for early diagnosis of COPD. ${ }^{6}$ However, it seems that the most preferable option is to provide general practitioners with high-quality 
spirometry validated by specialists. ${ }^{7}$ In a more recent study directly comparing two strategies for early identification of COPD in primary health care, it was shown that performing spirometry in a population selected by general practitioners who have undergone special training is more effective compared with an open spirometry program. ${ }^{8}$

The prevalence of COPD varies across countries and depends on the exposure of the general population to risk factors for COPD, especially smoking. ${ }^{1}$ In the Burden of Lung Disease (BOLD) study, it was shown that the overall prevalence of COPD was $10.1 \%$, with wide variations between countries. ${ }^{9}$ In a recent study in primary health care in central Greece, we showed that, in a large population sample involving about 20,000 subjects aged $>14$ years old, the prevalence of COPD was 350 cases per 10,000 residents. ${ }^{10}$

On the other hand, COPD mortality remains the primary endpoint of several studies. Worldwide, COPD was the sixth leading cause of death in 1990, and presently is the fifth. The Global Burden of Disease (GBD) study projects that, by 2020, COPD will become the third leading cause of death worldwide. ${ }^{11}$ In the study by Soriano et al, increasing severity of COPD was associated with increased mortality. Mortality rates per 1000 person-years for mild, moderate, and severe COPD were 54.3, 69.6, and 275.7, respectively, in women and $73.5,91.6$, and 380.2 in men. The highest mortality rate (458.2 per 1000 person-years) was observed in men aged over 65 years with severe COPD. ${ }^{12}$ Mortality has been associated with several parameters. For example, it has been shown that patients with greater number of comorbidities are at increased risk. ${ }^{13}$ Other parameters associated with increased COPD mortality are frequent COPD exacerbations ${ }^{14}$ or physical inactivity, ${ }^{15}$ and multidimensional systems, like the BODE index, which correlates with COPD mortality, have been developed. ${ }^{16}$ COPD mortality has been studied extensively in the two COPD mega trials, ie, the Towards a Revolution in COPD Health (TORCH) and the Understanding Potential Long-Term Impacts on Function with Tiotropium (UPLIFT ${ }^{\circledR}$ ) studies, which include a combined total of over 10,000 COPD patients. In the TORCH trial, overall mortality was $12.6 \%$ for the combination therapy group ${ }^{17}$ whereas in the UPLIFT study overall mortality was $14.9 \%$ in the tiotropium group. ${ }^{18}$

COPD is underdiagnosed, not only in its early stages, but even when lung function is severely impaired. Although it is responsible for high morbidity, mortality, and cost, it is often neglected by health care providers. Highlighting the course of COPD helps to raise the profile of the disease and may change long-held attitudes. ${ }^{19}$ In the current study, we followed up a cohort of newly diagnosed COPD patients in primary health care for two years. After two years, we assessed overall mortality and the differences between COPD patients who had died and those who were still alive. We also tried to identify the parameters associated with COPD mortality in primary health care in Greece.

\section{Materials and methods Study design}

The study was conducted at 14 primary health care centers in Thessaly, Greece, during a 14-month period from September 2007 to November 2008. The study group, which comprised two young physicians and an experienced chest physician with a special interest in COPD, visited each primary health care center during the first week of each month and offered spirometry to every subject who wanted to be examined. After performing spirometry, the subjects were examined by the chest physician who made a diagnosis of COPD according to existing COPD guidelines. Patients with a smoking history $<10$ pack-years, a previous diagnosis of COPD, inhaled medication for any reason, significant reversibility in spirometry, history of other respiratory disease, and upper or lower respiratory tract infection during the previous four weeks were excluded from the study. Three hundred and four patients with newly diagnosed COPD and the abovementioned inclusion criteria were asked if they wanted to be followed up for two years. Two hundred and sixty-three patients agreed to provide us with further communication details. Follow-up included phone contact and re-examination visits at predefined time intervals. The study was approved by the ethics committee of the University Hospital of Larissa and all subjects provided their informed consent.

\section{Initial visit}

A self-assessment questionnaire was completed upon arrival by all subjects, who subsequently underwent a physical examination, including assessment of body mass index, and, finally, prebronchodilation and post-bronchodilation spirometry. Body mass index was calculated as body weight divided by the square of height (expressed in $\mathrm{kg} / \mathrm{m}^{2}$ ).

The study questionnaire included questions about smoking habits, the presence of comorbidities (including coronary heart disease and psychological distress) and chronic respiratory symptoms (ie, cough, sputum production, wheezing, and dyspnea). Identification of comorbidities was based on the health records of each patient and the drugs received. Dyspnea was assessed using a modified (five-point) Medical Research Council dyspnea scale, as described previously. ${ }^{20}$ Subjects with a history of smoking $>100$ cigarettes during 
their lifetime were considered as smokers, whereas exsmokers were smokers who had quit smoking for at least 12 months. ${ }^{21}$ Smoking status was measured by pack-years, defined as the number of cigarettes smoked per day divided by 20 and multiplied by the number of years of smoking.

\section{Spirometry}

Spirometry was performed using a dry spirometer (KoKo Legend, Ferraris, UK), according to American Thoracic Society recommendations. ${ }^{21}$ Calibration checks were performed every morning 30 minutes before the beginning of the spirometry program. Spirometry testing was done by physicians who had undergone a special training program by two pneumonologists. Forced expiratory maneuvers were repeated until three reproducible acceptable tests were obtained, and the best forced expiratory volume in the first second $\left(\mathrm{FEV}_{1}\right)$, forced vital capacity $(\mathrm{FVC})$, and $\mathrm{FEV}_{1}$ to $\mathrm{FVC}$ ratio $\left(\mathrm{FEV}_{1} / \mathrm{FVC}\right)$ values were recorded. ${ }^{22} \mathrm{~A}$ bronchodilator reversibility test was performed in all patients with obstructive spirometry using $400 \mu \mathrm{g}$ of salbutamol. Obstructive spirometry was defined as an $\mathrm{FEV}_{1} / \mathrm{FVC}$ ratio $<0.7$, according to GOLD guidelines. ${ }^{1}$ An increase in $\mathrm{FEV}_{1}>12 \%$ and $>200 \mathrm{~mL}$ from baseline was considered significant. ${ }^{23}$

\section{Diagnosis of COPD}

Evaluation of patients and diagnosis of COPD were done by a chest physician who was present throughout the study. Diagnosis of COPD was based on smoking history, history of exposure to noxious particles or gases, compatible symptoms, and an $\mathrm{FEV}_{1} / \mathrm{FVC}$ ratio $<0.70$. Classification of COPD was based on post-bronchodilation $\mathrm{FEV}_{1}$, according to GOLD guidelines (Stage I, mild COPD FEV $\geq 80.0 \%$ predicted; Stage II, moderate COPD 50.0\% $\leq$ $\mathrm{FEV}_{1}<80.0 \%$ predicted; Stage III, severe COPD 30.0\% $\leq \mathrm{FEV}_{1}<50.0 \%$ predicted; Stage IV, very severe COPD $30.0 \% \leq \mathrm{FEV}_{1}$ or $\mathrm{FEV}_{1}<50.0 \%$ predicted with respiratory failure). After the diagnosis, the experienced physician prescribed inhaled medication for the patients according to their stage of disease and GOLD guidelines. ${ }^{1}$

\section{Follow-up}

Follow-up visits included phone contact and re-examination visits. Phone contact was made every six months in order to assess the vital status of the patient. Re-examination visits were scheduled after phone contact with the patient every year after the initial visit. The examination visit included completion of a structured questionnaire and performance of prebronchodilation and post-bronchodilation spirometry.
The questionnaire included questions about current smoking status, presence of respiratory symptoms (eg, cough, sputum production, wheezing, and dyspnea), adherence with previously described treatment, and number of exacerbations with or without hospitalization during the previous year. Adherence with treatment was defined as receiving the prescribed medicines for over $80 \%$ of the year (over 10 months). Patients who missed one of the examination visits were excluded from the analysis.

\section{Statistical analysis}

Demographic data regarding each visit are presented as the mean \pm standard deviation or median (interquartile range) for normally and skewed data, respectively. Comparison of proportions was performed using the Chi-square test, whereas differences in numerical variables between two groups were checked using the unpaired $t$-test or Mann-Whitney $\mathrm{U}$ test for normal and skewed data, respectively. When comparison between surviving and deceased patients with COPD was performed, the two groups differed in terms of age, body mass index, cough, sputum production, and coronary heart disease comorbidity at a statistical significance level of $P<0.1$. These variables were further included in a logistic regression model assessing mortality at two years. Data were analyzed using SPSS 15.0 for Windows (SPSS Inc, Chicago, IL). $P$ values $<$ 0.05 were considered to be statistically significant.

\section{Results}

The flow chart of the study is presented in Figure 1. Initially, 263 patients were included in the study. Ninety-nine patients were lost to follow-up during the first year and 46 during the second year. As a result, 145 patients were not included in the analysis, leaving 118 patients (44.9\%) for analysis. Of the remaining 118 patients, 17 died during the first year and 16 during the second year (Figure 1). Overall two-year mortality was $27.9 \%$ (33 of 118 patients).

Demographic data for the study population are presented in Table 1. Two years after initial diagnosis, the proportion of current smokers decreased significantly (51\% versus $32 \%, P<0.05)$, and the proportion of ex-smokers increased significantly ( $49 \%$ versus $68 \%, P<0.05$ ). However, there was no statistically significant difference in the proportions of respiratory symptoms, and no significant change in spirometric values. The average number of exacerbations for the study population was one exacerbation for both the first year and the second year, but only $59 \%$ and $68 \%$ of patients showed adherence with COPD treatment at year 1 and year 2 , respectively. 
263 newly diagnosed COPD patients were included in the study

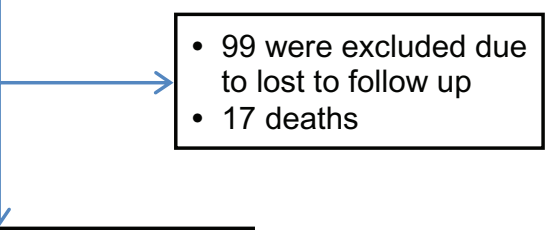

147 were examined after one year

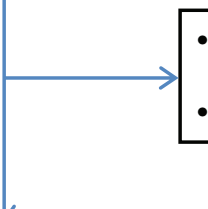

- 48 were excluded due to lost to follow up

- 16 deaths

Figure I Flow chart of the study.

Figure 2 shows the distribution of patients according to COPD stage for each visit, indicating that the distribution remains similar at all visits, with stage II patients being more prevalent.

With regard to baseline comorbidity, most patients had arterial hypertension (over 90\%), with coronary heart disease being the second most prevalent comorbidity (about $40 \%$ ). Other comorbidities with a lower prevalence included

hyperlipidemia, diabetes mellitus, arrhythmia, and depression (Figure 3).

Table 2 shows the differences in baseline characteristics between patients with COPD who did not survive and those who were still alive two years after the initial visit. There were no differences between the two groups, except for the proportion of patients with cough, sputum production, coronary heart disease comorbidity, and age, all being higher in the group of COPD patients who did not survive $(P<0.1)$.

It was shown in a logistic regression analysis model that age and coronary heart disease comorbidity was significantly associated with two-year mortality. The older the age and the higher the comorbidity from coronary heart disease, the higher the odds ratio for death (1.08 times for every year of age and 2.5 for coronary heart disease comorbidity) (Table 3 ).

\section{Discussion}

The results of the current study indicate that mortality from COPD remains significantly high in primary health care in Greece. The overall mortality rate of patients with COPD in the current study was $28 \%$, and the proportion of patients who were adherent with treatment remains low. Patients with COPD who did not survive had similar characteristics to those of patients who did survive, except for the presence of cough and sputum. The two-year mortality in this cohort of patients with COPD was associated with age and coronary heart disease comorbidity.

Table I Demographic data of sample

\begin{tabular}{|c|c|c|c|}
\hline Variables & Visit I & Visit 3 & $P$ value \\
\hline$n$ & 118 & 85 & \\
\hline Age & $74(68-79)$ & $73(68-78)$ & NS \\
\hline BMI & $28.06(25.82-31.14)$ & $28.37(26.57-31.14)$ & NS \\
\hline \multicolumn{4}{|l|}{ Smoking status } \\
\hline Current smoker & $60(50.85 \%)$ & 27 (31.76\%) & $<0.05$ \\
\hline Ex-smoker & $58(49.15 \%)$ & $58(68.24 \%)$ & $<0.05$ \\
\hline Cough & 91 (77.12\%) & $70(82.35 \%)$ & NS \\
\hline Sputum production & 89 (75.42\%) & 67 (78.82\%) & NS \\
\hline Wheezing & 67 (56.78\%) & $44(51.76 \%)$ & NS \\
\hline Dyspnea & 114 (96.61\%) & 81 (95.29\%) & NS \\
\hline $\mathrm{MRC}$ & $\mathrm{I}(\mathrm{I}-2)$ & $I(I-I)$ & NS \\
\hline FEV (\%pred) & $59.13( \pm 15.61)$ & $62.58( \pm 18.67)$ & NS \\
\hline FVC (\%pred) & $71.17( \pm 15.44)$ & $70.58( \pm 17.06)$ & NS \\
\hline $\mathrm{FEV}_{1} / \mathrm{FVC}$ & $65.45(56.03-69.93) *$ & $68.40(61.90-69.79) *$ & $<0.05$ \\
\hline PEF (\%pred) & $55.06( \pm|8.4|)$ & $57.76( \pm 20.96)$ & NS \\
\hline $\mathrm{FEF}_{25-75}$ (\%pred) & $36.00(23.75-47.00)$ & $40.00(26.50-55.00)$ & NS \\
\hline Average number of exacerbations & - & $\mathrm{I}(\mathrm{I}-2)$ & NS \\
\hline Adherence with treatment & - & $58(68.24 \%)$ & NS \\
\hline Hospital admissions & - & $18(21.18 \%)$ & NS \\
\hline Hospitalizations & - & $6(7.06 \%)$ & NS \\
\hline Number of deaths & - & 16 & \\
\hline
\end{tabular}

Abbreviations: IQR, interquartile range; BMI, body mass index; MRC, Medical Research Council; NS, not statistically significant; FEV , forced expiratory volume in the first second; FVC, forced vital capacity; FEV,/FVC, FEV, to FVC ratio; PEF, peak expiratory flow; $\mathrm{FEF}_{25-75}$, mid forced expiratory flow; \%pred, percent predicted. 


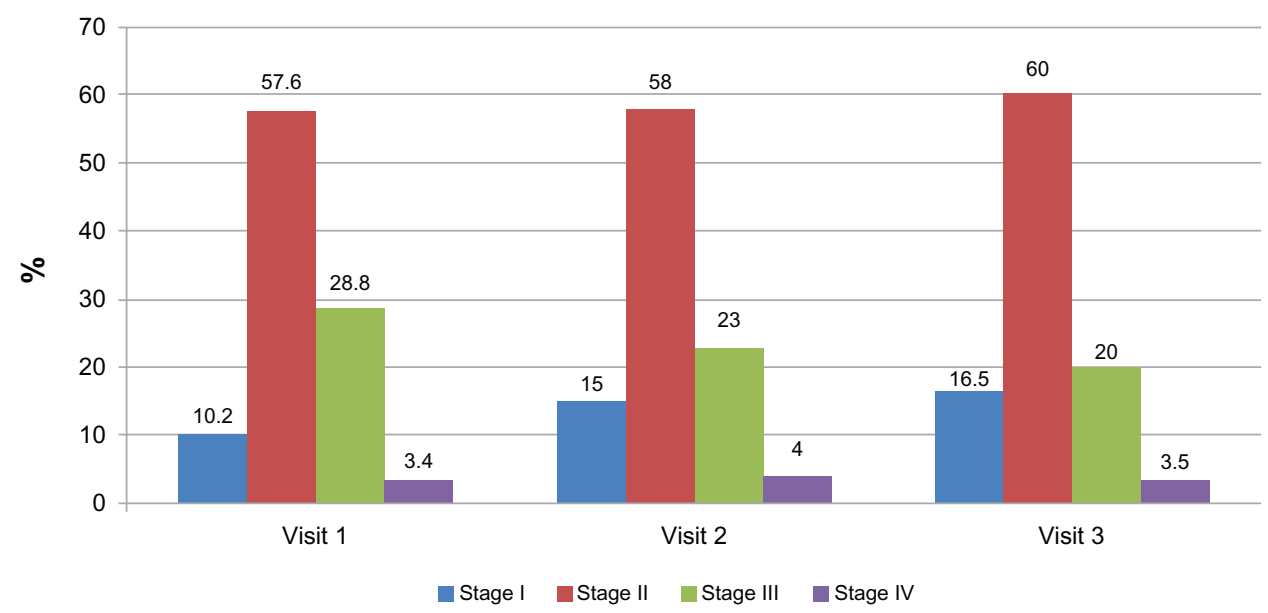

Figure 2 Distribution according to stages of chronic obstructive pulmonary disease in each visit.

Interestingly, in this cohort, the mortality rate from COPD was high, reaching $28 \%$, which is much higher compared with the mortality rate quoted in the TORCH and UPLIFT studies. In TORCH, the proportion of deaths from any cause was $12.6 \%$ for the combination therapy group, $13.5 \%$ for the salmeterol group, $16.0 \%$ for the fluticasone group, and $15.2 \%$ for the placebo group, ${ }^{17}$ whereas in the UPLIFT study, the mortality rate was $14.9 \%$ in the tiotropium group and $16.5 \%$ in the placebo group. ${ }^{18}$ However, there are trials with higher mortality rates for COPD. For example, the mortality rate was $26 \%$ in a study by Celli et al. ${ }^{16}$ One possible explanation for the high mortality rate in our cohort was the low percentage of patients with COPD who were adherent with treatment (about 60\%) and the fact that all these patients had limited access to specialist pulmonologists and tertiary hospitals.

Another interesting finding in our study was the high percentage of patients with COPD who quit smoking and the low percentage of patients who adhered with treatment. In previous studies, it has been reported that smoking cessation advice resulted in high smoking cessation rates in patients with airflow obstruction. ${ }^{24}$ On the other hand, although all patients were newly diagnosed, the percentage of adherence with treatment one year after the initial visit was only about $60 \%$. Data from the TORCH study indicate that adherence with treatment is an important parameter directly associated with COPD mortality and admission to hospital due to COPD exacerbation. In that study, it was shown that the percentage of deaths was higher in the group with poor adherence to treatment, and that adherence is associated with reduced risk of death and admission to hospital due to COPD exacerbation. ${ }^{25}$ However, despite the low percentage of adherence with treatment in our cohort, we did not find an association between this parameter and COPD mortality.

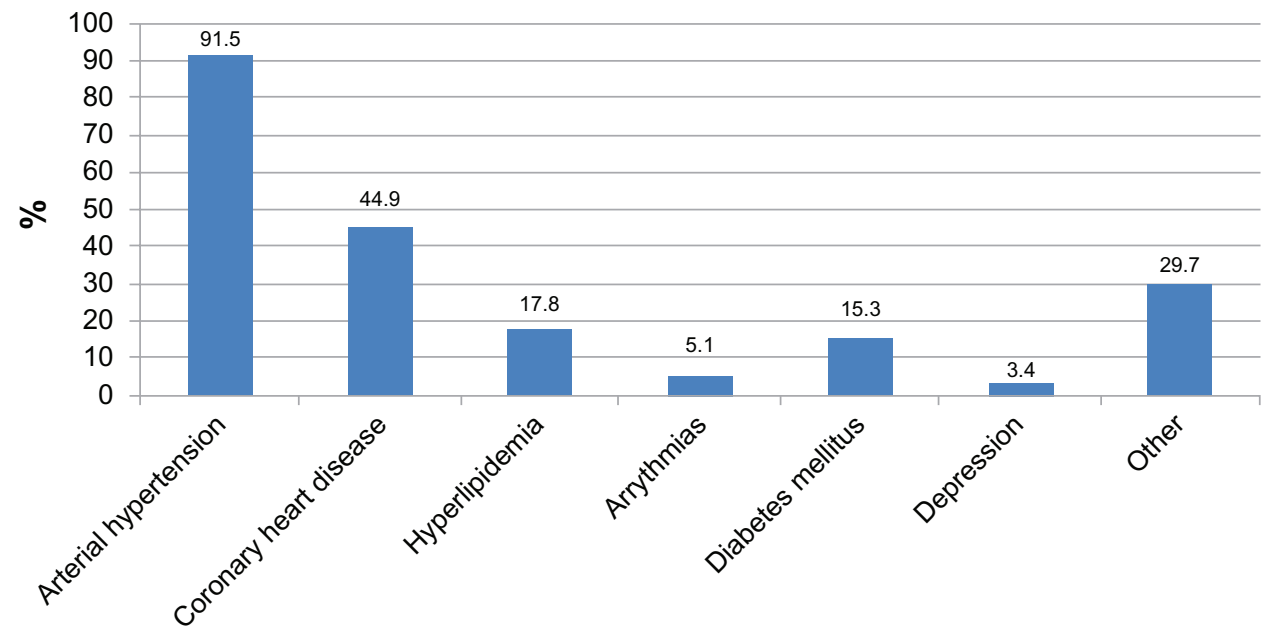

Figure 3 Distribution of comorbidities among study participants. 
Table 2 Baseline characteristics of COPD patients who died

\begin{tabular}{|c|c|c|c|}
\hline Variables & $\begin{array}{l}\text { Deceased } \\
\text { COPD patients }\end{array}$ & $\begin{array}{l}\text { Surviving } \\
\text { COPD patients }\end{array}$ & $P$ value \\
\hline $\mathrm{n}$ & 33 & 85 & \\
\hline Age & $74.4(8.1)$ & $71.7(7.1)$ & $<0.1$ \\
\hline BMI & $28.0(5.8)$ & $28.3(3.3)$ & NS \\
\hline \multicolumn{4}{|l|}{ Smoking status } \\
\hline Current smoker & $20(60.6 \%)$ & 40 (47.1\%) & NS \\
\hline Ex-smoker & I 3 (39.4\%) & 45 (52.9\%) & NS \\
\hline \multicolumn{4}{|l|}{ Comorbidities } \\
\hline Hypertension & 29 (87.9\%) & 79 (92.9\%) & NS \\
\hline Coronary & 19 (57.5\%) & 29 (42.4\%) & $<0.05$ \\
\hline \multicolumn{4}{|l|}{ Heart disease } \\
\hline Hyperlipidemia & $4(12.1 \%)$ & $17(20 \%)$ & NS \\
\hline Arrythmia & $2(6.1 \%)$ & $4(4.7 \%)$ & NS \\
\hline Diabetes mellitus & $4(12.1 \%)$ & 14 (I6.5\%) & NS \\
\hline Depression & $2(6.1 \%)$ & $2(2.4 \%)$ & NS \\
\hline Other & 10 (30.3\%) & 25 (29.4\%) & NS \\
\hline Cough & 30 (90.9\%) & 61 (7I.8\%) & $<0.05$ \\
\hline Sputum production & 30 (90.9\%) & 59 (69.4\%) & $<0.05$ \\
\hline Wheezing & $20(60.6 \%)$ & 47 (55.3\%) & NS \\
\hline Dyspnea & $33(100 \%)$ & 81 (95.3\%) & NS \\
\hline MRC & $\mathrm{I}(\mathrm{I}-\mathrm{I} .5)$ & $I(I-2)$ & NS \\
\hline COPD stage & & & NS \\
\hline Stage I & $3(9.1 \%)$ & $9(10.6 \%)$ & NS \\
\hline Stage II & 19 (57.6\%) & 49 (57.6\%) & NS \\
\hline Stage III & II (33.3\%) & $23(27.1 \%)$ & NS \\
\hline Stage IV & $0(0 \%)$ & $4(4.7 \%)$ & NS \\
\hline $\mathrm{FEV}_{1}$ (\%pred) & $60.1(15.2)$ & $58.7(15.8)$ & NS \\
\hline FVC (\%pred) & $71.0(62.5-80.5)$ & $73.0(57.0-83.0)$ & NS \\
\hline $\mathrm{FEV}_{1} / \mathrm{FVC}$ & $64.9(57.4-68.9)$ & $65.8(53.9-69.0)$ & NS \\
\hline PEF (\%pred) & $54.9(17.2)$ & $57.9(18.2)$ & NS \\
\hline $\mathrm{FEF}_{25-75}(\%$ pred) & $35.5(22.8-47.5)$ & $36.0(24.3-46.80)$ & NS \\
\hline
\end{tabular}

Abbreviations: BMI, body mass index; MRC, Medical Research Council; FEV, forced expiratory volume in the first second; FVC, forced vital capacity; FEV/FVC, FEV, to FVC ratio; PEF, peak expiratory flow; $\mathrm{FEF}_{25-75}$, mid forced expiratory flow; \%pred, percent predicted.

According to the findings of the present study, patients with COPD who did not survive shared several common characteristics with patients who did survive. The only differences were presence of cough and sputum production. In a previous study examining the characteristics of adults dying from COPD, it was shown that death from COPD was more likely to occur among current smokers, and that adults dying with COPD were more likely to be underweight. ${ }^{26}$ Moreover, it has been shown that the presence of mucus production is related to a rapid decline in $\mathrm{FEV}_{1}$ and that sputum production can predict COPD-related mortality. ${ }^{26}$ Our findings are in accordance with these data, ie, cough and sputum production were more prevalent in patients who did not survive.

Factors associated with mortality in patients with COPD include body composition, ${ }^{27}$ number of exacerbations, ${ }^{14}$ rapid decline in $\mathrm{FEV}_{1}$, ${ }^{28}$ and the presence of comorbidities. ${ }^{13}$ In a study including about 40,000 subjects with COPD, it was shown that men had lower survival rates compared with women after hospitalization for exacerbation of COPD. ${ }^{29}$ In addition, there are studies with multidimensional assessment of COPD patients in which mortality rate has been investigated. For example, survival has been associated with the BODE index, ${ }^{16}$ whereas it was shown in a recent cluster analysis that the "severe respiratory COPD" phenotype had a higher probability of death compared with the other two phenotypes. ${ }^{30}$ However, in our study, factors related to mortality with COPD were age and coronary heart disease. Indeed, patients with COPD are at increased risk of cardiovascular disease and, in turn, cardiovascular disease contributes significantly to morbidity and mortality in COPD. ${ }^{31,32}$ All these data indicate that COPD mortality is related to several aspects of the disease, and all these parameters may have an additive role in the overall probability of death in patients with COPD. It has been proposed that in primary health care, general practitioners should be directed to the identification and treatment of comorbidity in patients with COPD. ${ }^{33}$

\section{Limitations}

Our study is the first, to our knowledge, to investigate mortality among patients with COPD in primary health care, but has some limitations. One is the low proportion of subjects included in the analysis, with final inclusion of only 118 patients, although 263 patients were included

Table 3 Parameters associated with two-year mortality

\begin{tabular}{|c|c|c|c|c|c|c|c|c|}
\hline & \multirow[t]{2}{*}{ B } & \multirow[t]{2}{*}{ SE } & \multirow[t]{2}{*}{ Wald } & \multirow[t]{2}{*}{ df } & \multirow[t]{2}{*}{ Sig } & \multirow[t]{2}{*}{$\operatorname{Exp}(B)$} & \multicolumn{2}{|c|}{ 95\% Cl for $\operatorname{Exp}(\mathrm{B})$} \\
\hline & & & & & & & Lower & Upper \\
\hline \multicolumn{9}{|l|}{ Variables in equation } \\
\hline Age & 0.084 & 0.032 & 6.791 & I & 0.009 & 1088 & 1.021 & 1.159 \\
\hline Cough (yes) & 1.255 & 0.793 & 2.504 & I & 0.114 & 3.508 & 0.741 & 16.597 \\
\hline Sputum production (yes) & $0.78 \mathrm{I}$ & 0.776 & 1.012 & I & 0.315 & 2.183 & 0.477 & 9.991 \\
\hline CHD (yes) & 0.934 & 0.469 & 3.972 & I & 0.046 & 2.545 & 1.016 & 6.378 \\
\hline Constant & 9.328 & 2.535 & $|3.54|$ & I & 0.000 & $11,249.667$ & & \\
\hline
\end{tabular}

Notes: Death $=$ I, survival $=0$.

Abbreviations: $\mathrm{Cl}$, confidence interval; $\mathrm{CHD}$, coronary heart disease. 
initially. Secondly, there are no data concerning the causes of death and, as a result, COPD-related mortality cannot be estimated. Moreover, there is no registry of death certificates in Greece that could help follow the rest of the group. Therefore, mortality rate could fluctuate widely from around $13 \%$, if all of those patients lost to follow-up survived, up to $68 \%$ if all those lost to follow-up died. As a consequence, mortality rates should be treated cautiously. However, age and coronary heart disease comorbidity did correlate with mortality, and we estimate that a prospective study design, careful selection of COPD patients, and strict inclusion criteria would add value to the impact of the results of the current study.

\section{Conclusion}

This prospective cohort study of patients with COPD in primary health care shows that the most significant determinants of two-year mortality are age and coronary heart disease. Two years after initial diagnosis, a high proportion of patients with COPD had quit smoking, whereas adherence with treatment remained low. Given that identification of the predictors of COPD mortality remains an uncertain and complex topic, ${ }^{34}$ and the fact that implementation of long-term programs concerning COPD in primary health care has an important impact in several aspects of the disease, ${ }^{35}$ we estimate that intensive follow-up of patients with COPD in primary health care in Greece is essential.

\section{Acknowledgments}

The authors wish to thank Eleni Souloukou and Anna Toutoudaki for their secretarial support throughout the study.

\section{Disclosure}

The authors declare that they have no competing interests in this work.

\section{References}

1. Rabe KF, Hurd S, Anzueto A, et al. Global strategy for the diagnosis, management, and prevention of chronic obstructive pulmonary disease: GOLD executive summary. Am J Respir Crit Care Med. 2007;176(6):532-555.

2. Soriano JB, Zielinski J, Price D. Screening for and early detection of chronic obstructive pulmonary disease. Lancet. 2009;374(9691):721-732.

3. Van Schayck CP, Loozen JM, Wagena E, Akkermans RP, Wesseling GJ. Detecting patients at a high risk of developing chronic obstructive pulmonary disease in general practice: cross sectional case finding study. BMJ. 2002;324(7350):1370.

4. Price DB, Tinkelman DG, Nordyke RJ, Isonaka S, Halbert RJ. Scoring system and clinical application of COPD diagnostic questionnaires. Chest. 2006;129(6):1531-1539.

5. Martinez FJ, Raczek AE, Seifer FD, et al. Development and initial validation of a self-scored COPD Population Screener Questionnaire (COPD-PS). COPD. 2008;5(2):85-95.
6. Buffels J, Degryse J, Heyrman J, Decramer M. Office spirometry significantly improves early detection of COPD in general practice: the DIDASCO study. Chest. 2004;125(4):1394-1399.

7. Enright P. Provide GPs with spirometry, not spirometers. Thorax. 2008;63(5):387-388.

8. Konstantikaki V, Kostikas K, Minas M, et al. Comparison of a network of primary care physicians and an open spirometry programme for COPD diagnosis. Respir Med. 2011;105(2):274-281.

9. Buist AS, McBurnie MA, Vollmer WM, et al. International variation in the prevalence of COPD (the BOLD Study): a population-based prevalence study. Lancet. 2007;370(9589):741-750.

10. Minas M, Koukosias N, Zintzaras E, Kostikas K, Gourgoulianis KI. Prevalence of chronic diseases and morbidity in primary health care in central Greece: an epidemiological study. BMC Health Serv Res. 2010;10:252.

11. Murray CJ, Lopez AD. Alternative projections of mortality and disability by cause 1990-2020: Global Burden of Disease Study. Lancet. 1997;349(9064):1498-1504.

12. Soriano JB, Maier WC, Egger P, et al. Recent trends in physician diagnosed COPD in women and men in the UK. Thorax. 2000;55(9):789-794.

13. Mannino DM, Thorn D, Swensen A, Holguin F. Prevalence and outcomes of diabetes, hypertension and cardiovascular disease in COPD. Eur Respir J. 2008;32(4):962-969.

14. Soler-Cataluna JJ, Martinez-Garcia MA, Roman Sanchez P, Salcedo E, Navarro M, Ochando R. Severe acute exacerbations and mortality in patients with chronic obstructive pulmonary disease. Thorax. 2005;60(11):925-931.

15. Waschki B, Kirsten A, Holz O, et al. Physical activity is the strongest predictor of all cause mortality in patients with chronic obstructive pulmonary disease: a prospective cohort study. Chest. 2011;140(2):331-342.

16. Celli BR, Cote CG, Marin JM, et al. The body-mass index, airflow obstruction, dyspnea, and exercise capacity index in chronic obstructive pulmonary disease. $N$ Engl J Med. 2004;350(10): 1005-1012.

17. Calverley PM, Anderson JA, Celli B, et al. Salmeterol and fluticasone propionate and survival in chronic obstructive pulmonary disease. N Engl J Med. 2007;356(8):775-789.

18. Tashkin DP, Celli B, Senn S, et al. A 4-year trial of tiotropium in chronic obstructive pulmonary disease. $N$ Engl J Med. 2008;359(15):1543-1554.

19. Chapman KR, Mannino DM, Soriano JB, et al. Epidemiology and costs of chronic obstructive pulmonary disease. Eur Respir J. 2006;27(1):188-207.

20. Mahler DA, Wells CK. Evaluation of clinical methods for rating dyspnea. Chest. 1988;93(3):580-586.

21. Tzanakis N, Anagnostopoulou U, Filaditaki V, Christaki P, Siafakas N. Prevalence of COPD in Greece. Chest. 2004;125(3): 892-900.

22. [No authors listed]. Standardization of spirometry, 1994 update. American Thoracic Society. Am J Respir Crit Care Med. 1995;152(3):1107-1136.

23. Bateman ED, Hurd SS, Barnes PJ, et al. Global strategy for asthma management and prevention: GINA executive summary. Eur Respir J. 2008;31(1):143-178.

24. Bednarek M, Gorecka D, Wielgomas J, et al. Smokers with airway obstruction are more likely to quit smoking. Thorax. 2006;61(10): 869-873.

25. Vestbo J, Anderson JA, Calverley PM, et al. Adherence to inhaled therapy, mortality and hospital admission in COPD. Thorax. 2009;64(11):939-943.

26. Meyer PA, Mannino DM, Redd SC, Olson DR. Characteristics of adults dying with COPD. Chest. 2002;122(6):2003-2008.

27. Slinde F, Gronberg A, Engstrom CP, Rossander-Hulthen L, Larsson S. Body composition by bioelectrical impedance predicts mortality in chronic obstructive pulmonary disease patients. Respir Med. 2005;99(8):1004-1009. 
28. Mannino DM, Reichert MM, Davis KJ. Lung function decline and outcomes in an adult population. Am J Respir Crit Care Med. 2006;173(9):985-990.

29. Gonzalez AV, Suissa S, Ernst P. Gender differences in survival following hospitalisation for COPD. Thorax. 2011;66(1):38-42.

30. Garcia-Aymerich J, Gomez FP, Benet M, et al. Identification and prospective validation of clinically relevant chronic obstructive pulmonary disease (COPD) subtypes. Thorax. 2011;66(5):430-437.

31. Maclay JD, McAllister DA, Macnee W. Cardiovascular risk in chronic obstructive pulmonary disease. Respirology. 2007;12(5):634-641.

32. Patel AR, Hurst JR. Extrapulmonary comorbidities in chronic obstructive pulmonary disease: state of the art. Expert Rev Respir Med. 2011;5(5):647-662.
33. van der Molen T. Co-morbidities of COPD in primary care: frequency, relation to COPD, and treatment consequences. Prim Care Respir J. 2010;19(4):326-334.

34. Celli BR. Predictors of mortality in COPD. Respir Med. 2010;104(6): 773-779.

35. Kinnula VL, Vasankari T, Kontula E, Sovijarvi A, Saynajakangas O, Pietinalho A. The 10-year COPD programme in Finland: effects on quality of diagnosis, smoking, prevalence, hospital admissions and mortality. Prim Care Respir J. 2011;20(2):178-183.

\section{Publish your work in this journal}

The International Journal of General Medicine is an international, peer-reviewed open-access journal that focuses on general and internal medicine, pathogenesis, epidemiology, diagnosis, monitoring and treatment protocols. The journal is characterized by the rapid reporting of reviews, original research and clinical studies across all disease areas.
A key focus is the elucidation of disease processes and management protocols resulting in improved outcomes for the patient. The manuscript management system is completely online and includes a very quick and fair peer-review system. Visit http://www.dovepress.com/ testimonials.php to read real quotes from published authors.

Submit your manuscript here: http://www.dovepress.com/international-journal-of-general-medicine-journal 